\title{
Impact of Metabolic Syndrome on the Quality of Life of Menopausal Women
}

Pilar Orgaz ${ }^{1, *}$, Pablo Bermejo $^{2}$, Pedro J. Tárraga ${ }^{3}$ and Miguel A. Tricio ${ }^{1}$

${ }^{1}$ Primary Care Consultation, Tarancón, Cuenca, Spain

${ }^{2}$ Computing Systems Department, University of Castilla-La Mancha, Spain

${ }^{3}$ Primary Care Management Office, Albacete, Spain

\begin{abstract}
Background: Evaluating health-related quality of life is knowing the impact a disease has on patients' perception of their well-being. Health perception worsens with age and an increasing number of chronic diseases, which occurs with metabolic syndrome, whose prevalence reaches $40-50 \%$ after menopause. Thus, knowing the repercussion of this disease on life's quality will permit to adopt strategies to improve the health results.
\end{abstract}

Objective: Determining the health perception of menopausal women with metabolic syndrome and the factors implicated.

Methods: Cross-sectional study in Primary Health Care in the province of Cuenca (Spain). By random sampling, 400 menopausal women aged $\geq 45$ years with metabolic syndrome (NCEP-ATP III) were selected. Survey SF- 12 was used to evaluate physical and mental health's general aspects.

Results: Health perception was regular for $52 \%$ but good for $40.5 \%$. The mean score of the physical summary component was below the mean for the Spanish population, while the mental component was over the mean for patients over 65 years. ANOVA showed significant differences for the physical summary component for age $(p<0.001)$. Women in the $45-54$ age groups obtained a better result for this component than those aged over 65 . No differences were found for age groups in the mental component.

Conclusions: Menopausal women with metabolic syndrome have a regular health perception being the physical health worse than the mental one. Physical health is better in younger women with studies, without obesity, diabetes, osteoarthritis, osteoporosis or bronchial pathology. Mental health is better in women without hypertriglyceridaemia or psychic disease.

Keywords: Quality of life; Metabolic syndrome; Menopause; Mental health; Observational study; Women

\section{Background}

The obesity in adults and children is associated with several Metabolic Syndrome (MetS) components in adults, increasing coronary artery disease [1-3]. MetS, which appeared as an epidemic in parallel with the obesity epidemic, entails a higher cardiovascular risk for women, especially menopausal women, as it doubles the risk of developing cardiovascular disease, and multiplies by the risk of diabetes mellitus [4].

The health-related quality of life (HRQoL) concept, includes the "patient's perception" as a need to evaluate health outcomes. To evaluate this perception, valid and reliable measurement instruments must be developed that provide scientific evidence in health decision making [5]. The HRQoL concept is multidimensional and its evaluation represents the impact that a disease and its treatment have on patients' perceptions of their health and well-being [6]. At the beginning of the 1980s, health profiles appeared; e.g., SF-36, a generic instrument to measure the HRQoL that can be applied to a wide range of populations and afflictions. It has eight dimensions that provide valuable information about very important aspects of life for patients, and has been applied to clinical trials and research [7]. These profiles came with instructions about how to complete them, and a series of items and response options. Items can be grouped into dimensions, and the scores of each item are usually added up to obtain an overall score for each dimension. Response options are generally dichotomic (yes/no) or come as a Likert scale (with 4-7 ordinal response options).

In clinical practice, HRQoL measuring instruments should never be an obstacle, and should be gradually included to monitor and evaluate the health of patients with chronic diseases because the information they offer complements that collected in usual clinical practice and helps make future decisions on health. We should select the most suitable instrument according to population characteristics, the study objective, the survey contents, etc. They should be easy to administer and understand in real clinical practice conditions [7].

Vilagut, et al. [8] concluded that it can be recommended in both research and clinical practice as it is one of the most widespread generic instruments used in Spain in descriptive studies that measure the impact on HRQoL and for evaluating therapeutic interventions, and has also been used to validate new measuring instruments. There is a short version, "SF-12 questionnaire", that can be answered in 2 minutes and allows to evaluate the general physical and mental concepts in studies for which the SF-36 proved too long [9].

\section{Methods}

This observational, descriptive and cross-sectional study, with no control group, was carried out in a primary health care. 716 menopausal

*Corresponding author: Pilar Orgaz, Primary Care Consultation, Tarancón., C/ Camino Corral de Almaguer, CEDT Tarancón, Cuenca, Spain, E-mail: mporgaz@ sescam.jccm.es

Received September 27, 2015; Accepted November 02, 2015; Published November 06, 2015

Citation: Orgaz P, Bermejo P, Tárraga PJ, Tricio MA (2015) Impact of Metabolic Syndrome on the Quality of Life of Menopausal Women. J en Pract 3: 205. doi: 10.4172/2329-9126.1000205

Copyright: (ㅇ 2015 Orgaz P, et al. This is an open-access article distributed under the terms of the Creative Commons Attribution License, which permits unrestricted use, distribution, and reproduction in any medium, provided the original author and source are credited. 
women were randomly selected from 3108 aged $\geq 45$ years in a basic health zone of Tarancon city, in the province of Cuenca (CastillaLa Mancha, Spain). 442 women had MetS criteria by ATP-III, 2001. 42 of them were excluded by severe disease, terminal or psychiatric pathology, cognitive impairment or no authorisation. The study period was from January 2010 until March 2011.

The aim was to know the quality of life perceived by this population group and the factors implicated. With participants' informed consent, and authorization from the Health Centre and the Ethics Committee of Cuenca Hospital, data were collected on: age, years of menopause, level of education, profession, employment status, anthropometric data (weight, height, body mass index, waist circumference), lifestyles (alcohol, smoking and physical exercise), systolic and diastolic blood pressure, analytical data (fasting glucose, complete lipid profile, uric acid, etc.), associated diseases and treatment. The Morisky-GreenLevine test evaluated the therapeutic compliance. A personal interview was conducted to assess quality of life using the SF-12 health survey, which provides health profiles in both, the general population and in patients of a minimum age of 14 , in descriptive or evaluation studies. It is self-administered, but can be filled in during personal interviews, telephone interviews or on a computer, in 2 or less minutes.

It includes 12 items from eight dimensions of the SF-36: Physical Function [2], Social Function [1], Physical Role [2], Emotional Role [2], Mental Health [2], Vitality [1], Body Pain [1], and General Health [1].These response options form Likert-type scales that assess intensity or frequency. The number of response options ranges between 3 and 6 , depending on the item. This survey gets two summary scores, physical and mental score, that are normalized with values taken from population norms, and 50 (a standard deviation of 10) is the general population mean. Any values over or below 50 should be interpreted as better or worse values, respectively, than the reference population used. The physical and mental summary components, calculated with specific Spanish weightings, are valid and reliable, and the reference norms for these summaries facilitate the interpretation of the quality of life results evaluated with SF surveys in studies conducted in Spain [10].

The statistical analysis was done with the SPSS.19 software, and expressed the qualitative variables in frequencies and percentages, the qualitative variable in means \pm standard deviation, and also calculated the $95 \% \mathrm{CI}$ in the variables of interest. To compare means, the T-test (2 samples) and an ANOVA ( $\geq 3$ samples) were used. The Z-test was applied to compare proportions. The correlation analysis with the qualitative variables was done with $\mathrm{X} 2+\mathrm{Phi}$ for binomials, and Cramer's $\mathrm{v}$ test for multinomial, while Pearson or Spearman was employed with the quantitative variables. Linear regression was used for the related numerical variables.

\section{Results}

The mean age of the sample was 67 years $(66.93 \pm 10.49)$. The age distribution was: $45-54$ years, $13.75 \%$; $55-64$ years, $30.25 \%$; $65-74$ years, $29.05 \%$; $\geq 75$ years, $26.50 \%$.

The mean age at menopause was: $48.76 \pm 5.08$ years and $58.70 \%$ reported more than 14 years in that status. They were housewives (66.8\%) and retired (77.59\%).

The education level was: no studies (31\%); primary education (56.25\%), secondary education (10.25\%); university education (2.50\%).

Respect to lifestyles; $87 \%$ did not smoke, $91 \%$ did not drink alcohol, and $69 \%$ did physical exercise, predominantly an aerobic type. The time they spent exercising was less than 30 minutes/day for 32.4\%, 30-60 minutes/day for $55.4 \%$, and over 60 minutes/day for $12.2 \%$.

The anthropometric data were: weight $(77.68 \pm 13.41 \mathrm{~kg})$, height $(154.46 \pm 9.62 \mathrm{~cm})$, BMI $(40.41 \pm 12.63 \mathrm{~kg} / \mathrm{m} 2)$, waist circumference $(96.02 \pm 10.79 \mathrm{~cm})$, systolic blood pressure $(141.51 \pm 15.75 \mathrm{mmHg})$, diastolic blood pressure $(80.34 \pm 9.04 \mathrm{mmHg})$. Obesity prevalence was 91\% (IC95\% 90, 97-91, $02 \mathrm{p}<0.05)$ and its distribution by age group is showed in Figure 1.The obesity percentage was significantly higher in the retired women than in workers, with $97 \%$ accuracy. A statistically significant association $(\mathrm{p}<0.001)$ was found between obesity and being more limited when making moderate efforts, and obesity and doing fewer tasks than wished, and also between age and being more limited in making moderate physical efforts. It was very significant that the obese participants answered less frequently that pain did not limit them at all in their daily activities, with $99.90 \%$ accuracy. Obesity was significantly associated with less vitality $(\mathrm{p}<0.01)$ and age $(\mathrm{p}<0.05)$ and hypertension with more than 25 years of menopause $(\mathrm{p}<0.05)$ and having a lower level of education, with $97 \%$ accuracy. Among those women aged over 65 years, high blood pressure was significantly more frequent $(\mathrm{p}<0.0001)$, as was diabetes mellitus type $2(\mathrm{p}<0.017)$. Diabetic women were more limited when walking up flights of stairs than those who were not (99.90\% accuracy).

High blood pressure (87.50\%), obesity (67\%), osteoarthritis (63\%), hypercholesterolaemia (61\%), hypertriglyceridaemia (54\%), mental disorders (33.10\%) and diabetes mellitus (32.50\%) were most prevalent than cardiovascular disease $(13.50 \%)$, and thyroid or bronchial pathologies (10\%). Of all the women, $60.50 \%$ took analgesics.

Morisky-Green test showed a good compliance in $59.25 \%$, higher in women aged $\geq 75$ years $(63.21 \%)$ than in the $45-54$ year-olds $(44.44 \%)$. The greater compliance of the elderly age group was significant, who still did daily tasks and did no fewer tasks than wished despite their physical or psychic problems ( $\geq 98 \%$ accuracy).

The results of SF-12 survey are shown in Table 1 . The mean of the physical and mental summary components according to the SF-12 was compared with the mean value of these components taken from the Spanish population (Figures 2 and 3, respectively).

\section{Conclusion}

The sample's distribution into age groups was quite homogeneous and representative of the population because of its random selection. The smaller percentage of women in the $45-54$ age groups is logical because the mean age of menopause in Spain is about $48 \pm 3$ years and younger women have less time to participate in studies.

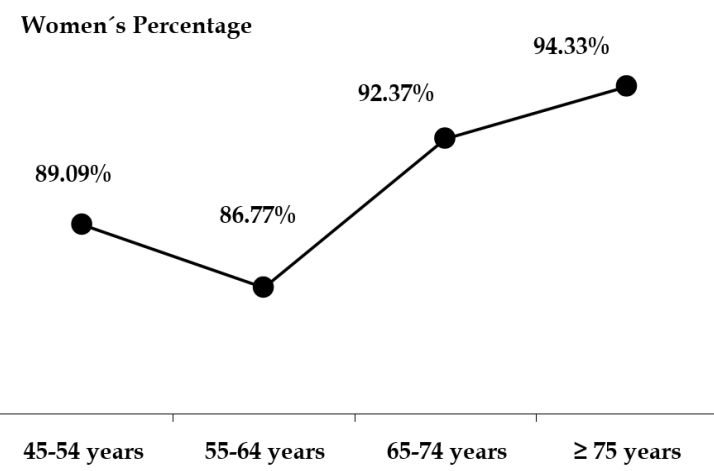

Figure 1: Obesity prevalence per age groups. 
The anthropometric data showed an obese and hypertensive group, but with quite healthy life styles as the vast majority reported no harmful habits, and almost 70\% did physical exercise regularly.

$86.8 \%$ had abdominal obesity, according to waist perimeter over 88 $\mathrm{cm}$, which is a much higher percentage than that reported by Romero et a1. $(66 \%)$, and it increased with age $(\mathrm{p}=0.031)$. It is well-known that loss of estrogen during the menopause is accompanied by a "weight increase" and by a "central redistribution of body fat", irrespectively of age and existence of obesity, facts which are influenced by years on menopause $[11,12]$. This study did not find a correlation between obesity and years of menopause, but observed a statistically significant association when comparing years of menopause in obese vs. nonobese women and it was stronger in the former.

The DORICA study [13] found that a group of women $>45$ years with a low level of education and an unfavourable socio-economic background proved to be a risk group for obesity, which peaked between 45-65 years.

It is known that a higher prevalence of obesity in women is caused by biological factors (pregnancy, menopause), psychological (eating disorder, depression, anxiety) and social and environmental (excessive intake). The metabolic changes that occur during menopause and contributing to metabolic syndrome, cannot be attributed solely to hormone deprivation, but also to genetics, the aging process per se (with a slowing of the metabolic rate of $4-5 \%$ /decade from age $48+$ a weight gain of $0.55 \mathrm{~kg} /$ year) and unhealthy habits (smoking, physical inactivity and a high calorie diet or rich in saturated fats). This study did not carry on an exhaustive analysis of the usual diet but several factors were regarded such as consumption of legumes, fruit, vegetables, meat, fish, dairy products, etc. As more than two thirds of the sample performed regular exercise, we cannot attribute high prevalence of obesity to this factor. However, we cannot rule out that in addition to genetics, over the years and the hormonal changes of menopause, obesity is mainly influenced by excessive caloric intake.

Quality of life has become an objective of health and social policies, and is a goal for the state of well-being commonly employed in the general population. HRQoL includes people's valued judgement of their

\begin{tabular}{|l|l|}
\hline $\begin{array}{l}\text { General Health } \\
\text { (question 1) }\end{array}$ & $\begin{array}{l}\text { The health perception was regular in } 52 \% \text { but good in } \\
40.5 \%\end{array}$ \\
\hline $\begin{array}{l}\text { Physical Function } \\
\text { (questions 2 and 3) }\end{array}$ & $\begin{array}{l}\text { Most of women were very limited physically, especially } \\
\text { when walking upstairs (46.3\%). }\end{array}$ \\
\hline $\begin{array}{l}\text { Physical Role } \\
\text { (questions 4 and 5) }\end{array}$ & $\begin{array}{l}\text { Health interfered with work and other tasks; indeed } 46 \% \\
\text { did fewer tasks than wished, although } 67 \% \text { did them all. }\end{array}$ \\
\hline Body Pain (question 8) & $\begin{array}{l}\text { Pain did not interfere with daily activities for } 29.5 \% \text { and } \\
\text { only slightly for } 23 \% .\end{array}$ \\
\hline Vitality (question 10) & Over half the women only sometimes felt such energy. \\
\hline $\begin{array}{l}\text { Social Function } \\
\text { (question 12) }\end{array}$ & $\begin{array}{l}\text { Physical or emotional health problems never interfered } \\
\text { with the social life of 43\% but occasionally for } 22 \% .\end{array}$ \\
\hline $\begin{array}{l}\text { Emotional Role } \\
\text { (questions 6 and 7) }\end{array}$ & $\begin{array}{l}\text { Emotional problems had no negative effect on daily } \\
\text { activities for } 60 \% .\end{array}$ \\
\hline $\begin{array}{l}\text { Mental Health } \\
\text { (questions 9 and 11) }\end{array}$ & $\begin{array}{l}\text { Although } 57.3 \% \text { reported nervousness, } 76.5 \% \text { reported } \\
\text { rarely feeling sad or down. }\end{array}$ \\
\hline
\end{tabular}

Table 1: Dimensions of the SF-12 health survey's results.

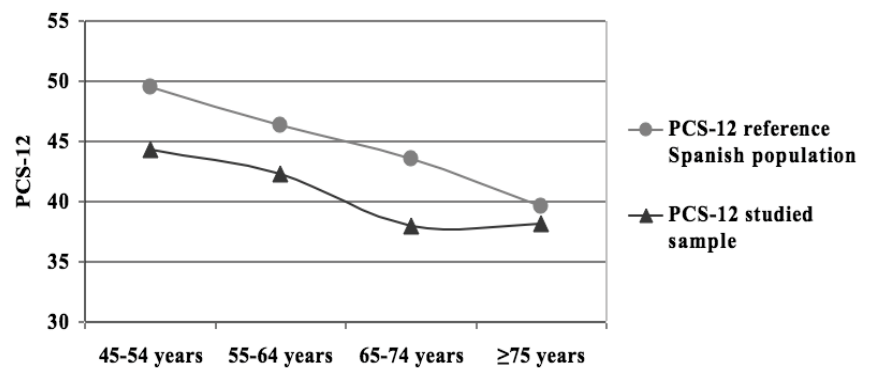

Figure 2: Mean scores of the SF-12 physical summary component per age group.

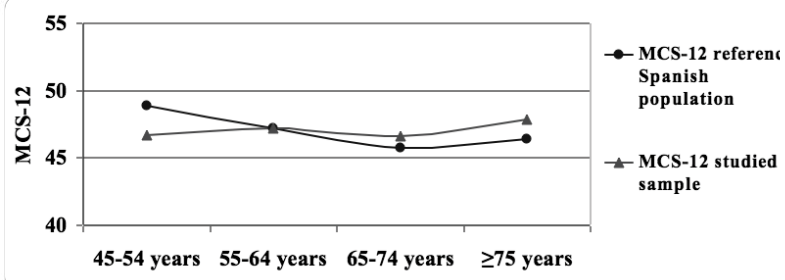

Figure 3: Mean scores of the SF-12 mental summary component per age group.

health status and the support they receive from their surroundings. The family of "SF" instruments to measure HRQoL is considered a reference pattern to develop and validate other HRQoL instruments. The Spanish version includes population norms that facilitate the interpretation of the scores obtained [10].

López García et al. [14] used a sample of 3.605 non-institutionalised people aged $\geq 60$ years founding that people who were overweight obtained worse scores in the physical dimension of survey SF-36, but not in its mental dimension, like we obtained with the short version (Table 2).

A study done with a United States population into the impact of obesity on HRQoL [15] obtained worse scores for overweight/obese patients in the SF-12 physical summary component compared to the mental one, even for patients with no known chronic diseases related with obesity, such as diabetes, hypertension, coronary heart disease and ictus.

Another study in a primary health care [16], evaluated the association between obesity and two HRQoL aspects, self-perception of health and psychological well-being, by two surveys: the NHP (Nottingham Health Profile) and the PGWB (Psychological General Well-Being) index. The mean NHP scores indicated a global moderate deterioration in health perceived in obese patients, and the affected areas were: pain, mobility and emotional reactions. The variables with the worst scores were female gender, age $>50$ years, low level of education and presence of a psychiatric pathology or osteoarthritis. The mean PGWB score indicated slight deterioration in psychological well-being, and female gender, anxiety and low level of education were associated with the worst scores.

Ramírez Vélez [17] reported a significant deterioration in quality of life which was related with morbidity risk factors in adults whose mean age was around 70 years, and was worse on the physical scales than on the mental ones. 
Several studies $[18,19]$ have reported a worse quality of life in patients with MetS, like the Italian QUOVADIS18 with 77.6\% of women whose mean age was 48 and severe obesity in $32 \%$, which found a strong association between worse quality of life in all the SF-36 domains and BMI, where the strongest association was with physical activity and the weakest one was with emotional role.

Another study in 325 Ecuadorian postmenopausal women 20, with mean age of 56 years and MetS (41.5\%), using the MenQol survey, concluded that the worst quality of life was associated with age and related conditions like obesity, hypertension and hyperglycaemia.

The SF-12 survey allowed us to obtain mean summary scores of the physical and mental components to compare their results with the Spanish population ones. This short questionnaire should be included in the clinical practice in primary health care because in only two minutes give us information about patient's health perception which is helping us to make important health decisions.

Although this is a descriptive cross-sectional study and we cannot to establish causal relationships, this study provides sufficient information to pose new work hypotheses.

The menopause is an interesting status in the woman's life. Approximately $40 \%$ of a woman's life is spent in that state, because the menopause occurs around the age of 50 and the life expectancy of women in Castilla-La Mancha is 85 years. It is also noteworthy that very few studies have been conducted in Spain that have dealt with loss of quality of life associated with MetS in the general population or in specific groups, as in this study.

In general, our results coincide with other studies, finding better outcomes in the mental component than the physical one. The mean value of the Physical Component summary Score, PCS-12, was below the mean Spanish population score in all age groups. The mean value of the Mental Component summary Score, MCS-12, was above the mean Spanish score for women $>65$ years. We found no differences in the mental component for age groups, although the physical one was significantly worse in $>65$ years group.

Obesity is the second most prevalent component of MetS in menopausal women, and is strongly associated with greater physical limitation for moderate efforts apart from age, for which we also found a significant association.

Based on these results, HRQoL policies should be implemented for menopausal women because they are an important population group with associated pathologies like obesity, diabetes, osteoarthritis, etc... with a particular deterioration of physical health. Prevention strategies of being overweight/abdominal obesity is stressed as it is one of the main components of MetS which increases the cardiovascular risk in the menopause at the same time is implicated in a worse health perception.

It is significant that all obese women have greater limitations to climb several floors, lower vitality and they perform less tasks than

\begin{tabular}{|c|c|c|c|c|}
\hline \multirow{2}{*}{ Unpaired t-test } & & $\mathbf{N}$ & CSF (SF-12) & CSM (SF-12) \\
\hline \multirow{2}{*}{ Obesity } & No & 36 & $46.21^{* * *}$ & 47.15 \\
\cline { 2 - 5 } & Yes & 364 & 39.61 & 47.08 \\
\hline \multicolumn{4}{|c}{${ }^{* * *} p<0.001$} \\
\hline
\end{tabular}

Table 2: Analysis between obesity and SF-12 survey's physical and mental components. desired, being limited by their pain. The variables associated with worst scores (lowest score) in the physical component summary of the SF12 compared with the mental, were: being over 65 , no studies, being obese, arthritis and diabetes mellitus; all these are matching results with several publications $[15,18,20]$. Although it is not very common to measure the quality of life related to health, due to the brevety of the SF-12 questionnaire it becomes easy to apply it in the overall assessment not only of menopausal women but of all patients, especially chronic, to know the perception of their health.

\section{Funding}

This work has been supported by the JCCM under regional project PEII-2014-049-P, and the MECD under national project TIN201346638-C3-3-P. These financial help was used for statistical analysis and interpretation of the results obtained.

\section{Acknowledgements}

This work was also partially supported by the Research Commission of the Integrated Care Manegement, in Albacete (Spain). Many thanks any Merry Chritsmas. Dra Ma Pilar Orgaz. The Research Comission Integrated Care, in Albacete" since this organization was the one which paid the bill of the article, and we wish to avoid ethical problems with it. We hope you can help us.

\section{References}

1. Acquadro C, Berzon R, Dubois D, Leidy NK, Marquis $P$, et al. (2003) Incorporating the patient's perspective into drug development and communication: an ad hoc task force report of the patient-reported outcomes (PRO) harmonization group meeting at the Food and Drug Aministration, Value Health 5: 522-531.

2. Ford ES, Giles WH, Dietz WH (2002) Prevalence of the metabolic syndrome among US adults: findings from the third National Health and Nutrition Examination Survey 287: 356-359.

3. Serra-Majem L, Aranceta J, Pérez Rodrigo C (2006) Prevalence and determinants of obesity in Spanish children and young people $\mathrm{Br} \mathrm{J}$ Nutr 96 67-72.

4. Carr MC (2013) The emergence of the metabolic syndrome with menopause. The Journal of Clinical Endocrinology and Metabolism 88: 2404-2411.

5. Testa M (1996) Current concepts:Assessment of Quality of Life Outcome. J Med 334: 835-840

6. Acquadro C, Berzon R, Dubois D (2001) PRO Harmonization Group Incorporating the patient's perspective into drug development and communication: an ad hoc task force report of the patient-reported outcomes (PRO) harmonization group meeting at the Food and Drug Administration, Value Health 5: 522-531.

7. Ware JE Jr, Sherbourne CD (1992) The MOS 36 item short-form health survey (SF-36) (I). Conceptual framework and item selection. Med Care 30: 473-483.

8. Vilagut G, Red IRYSS (2005) The Spanish version of the short form 36 Health survey: a decade of experience and new developments. Gac Sanit 19: 135 150 .

9. Ware JJR, Kosinski M, Keller SD (1996) A 12 item short-form health Survey: construction of scales and preliminary test of reliability and validity. Med Care 34: 220-33.

10. Vilagut G, Valderas JM, Ferrer M, Garin O, López García E, et al. (2008) Interpretation of SF-36 and SF-12 health questionnaires in Spain: physical and mental components. Med Clin 130: 726-735.

11. Romero R, Bonet J, de la Sierra, Aguilera A, Esopoh MT (2007) Study Investigators. Undiagnosed obesity in hypertension: clinical and therapeutic implications. Blood Press 16: 347-353.

12. Franklin RM, Ploutz Snyder J, Kanaley JA (2009) Longitudinal changes in abdominal fat distribution with menopause. Metabolism Clinical and Experimental 58: 311-315.

13. Aranceta J, Pérez Rodrigo C, Serra Majem L, Vioque J, Tur Marí JA, et al. (2004) Estudio DORICA: dislipemia, obesidad y riesgo cardiovascular. In Aranceta J, Foz M, Gil B, Jover E, Mantilla T, et al. (eds) Obesidad y riesgo cardiovascular, Estudio DORICA. Madrid. Panamericana 125-56. 
Citation: Orgaz P, Bermejo P, Tárraga PJ, Tricio MA (2015) Impact of Metabolic Syndrome on the Quality of Life of Menopausal Women. J en Pract 3: 205. doi: 10.4172/2329-9126.1000205

Page 5 of 5

14. López García, E Banegas, JR Gutiérrez, Fisacs JL, Pérez Regadera, et al. (2003) Relation between body weight and health-related quality of life among elderly in Spain. In J Obes Relat Metab Disord 276: 701-709.

15. Jia H, Lubetkin El (2005) The impact of obesity on health-related quality-of-life in the general adult US population. Journal of Public Health 27: 156-164.

16. Barajas Gutiérrez MA, Robledo Martín E, Tomás García N, Sanz Cuesta T, García Martín P, et al. (1998) Quality of life related to health and obesity in Primary Care Facility. Rev Esp Salud Pública 72: 221-31

17. Ramírez Vélez, R Agredo, RA Jerez, AM Chapal LY (2008) Health-related quality of life and conditions of health in non institutionalised elderly people in
Cali, Colombia. Rev Salud Pública 10: 529-536.

18. Corica F, Corsonello A, Apolone G, Luchetti M, Melchionda N, et al. (2006) The QUOVADIS STUDY GROUP. Construct validity of the short form-36 health survey and its relationship with BMI in obese outpatients. Obesity 14: 14291437.

19. Tziallas D, Kastanioti C, Savvas K, Kostapanos MS, Tziallas, et al. (2012) Evaluation of health related quality of life in patients with metabolic syndrome. Health Science Journal 6: 116-128.

20. Chedraui P, Hidalon L, Chavez D, Morocho N, Alvarado M, et al. (2007) Quality of life hmong postmenopausal Ecuatorian women participating in a metabolic syndrome screening program. Maturitas 56: 45-53. 